\title{
Mapping the inhomogeneity of the $U$ and Th distributions - using sample size concept in the field conditions
}

\author{
Madhulika Pathak, Shaibal Gupta, Debashis Bhattacharya, \\ M K Rao and B K Bhaumik* \\ Atomic Minerals Directorate for Exploration and Research, Department of Atomic Energy, \\ West Block VII, R K Puram, New Delhi-110 066, India \\ E-mail : bidhan_bhaumik@yahoo.co.in
}

\begin{abstract}
Indigenously fabricated portable gamma-ray spectrometer (PGRS) is used for the measurement of gamma activity of ${ }^{214} \mathrm{Bi}(1.76 \mathrm{MeV})$ and ${ }^{208} \mathrm{TI}(2.62 \mathrm{MeV})$, under field conditions in Mohar area, Shivpuri Distt. (MP). The energies are discriminated by using a Nal (TI) crystal of size $1.75^{\prime \prime} \times 2$ ". PGRS used to map the primordial elemental distributions shows reversals of concentration of thorium and uranium (represented by radium group) in field and lab analysis in many samples, which is attributed to the inhomogenity of distribution of these elements in the area. The concept of difference in the volume of dish shaped field sample and the randomly picked up sample from the field grid point ( $400 \mathrm{gm}$ in lab analysis) is utilized to interpret the inhomogenity of these elements. However interpretations are based on the assumption that these primordial elements $(U, T h)$ are in secular equilibrium and the terrain has low topographic relief.
\end{abstract}

Keywords : Portable gamma ray spectrometer, 1K MCA, U, Th distribution.

PACS No. : : 07.85.NC

\section{Introduction}

Uranium exploration is mainly based on gross gamma measurements. However, spectrometric data using different gamma-ray energies emitted by primordial elements $(U$, Th, ${ }^{40} \mathrm{~K}$ ) offer an additional advantage in discriminating uranium and thorium. In order to discriminate among $\mathrm{U}$, Th and $\mathrm{K}$ and to estimate their abundances, $\gamma$-ray spectrometric survey is found to be the most suitable [1]. Hence, following the recommendation of IAEA (1974), Vienna, a compact, portable, lightweight PGRS was developed by AMD [2] for in situ determination of $\mathrm{U}$, Th and $\mathrm{K}$ in the field.

\footnotetext{
* Corresponding Author
} 
While using the PGRS for survey in the field, certain uncertainties are there of which four main uncertainties have been identified as : (i) lack of secular equilibrium in the rock formations examined, (ii) radon migration and escape, (iii) instrument calibration and environmental geometrical problems resulting from the deviation from the plane and (iv) non uniformity in the distribution of radioactive material [3].

In the present study, with a view to eliminating uncertainties due to environmental geometrical problems, a terrain of low topographic relief is selected. In situ gamma ray spectroscopic measurements and the collection of grab samples from the grid locations followed by gamma ray spectrometric analysis in lab have been made with a view to mapping the inhomogeneities of radioelement distribution.

\section{Geological setting}

The area (centered around Mohar Cauldron) is located in southwest of Karera, $20 \mathrm{~km}$ on Sarsod-Pichore road off Shivpuri-Jhansi highway in Shivpuri district, Madhya Pradesh. It is exposed in the western part of Bundelkhand Gneissic Complex (BGC). Geological Survey of India [4] first reported the existence of this collapse cauldron within the Bundelkhand

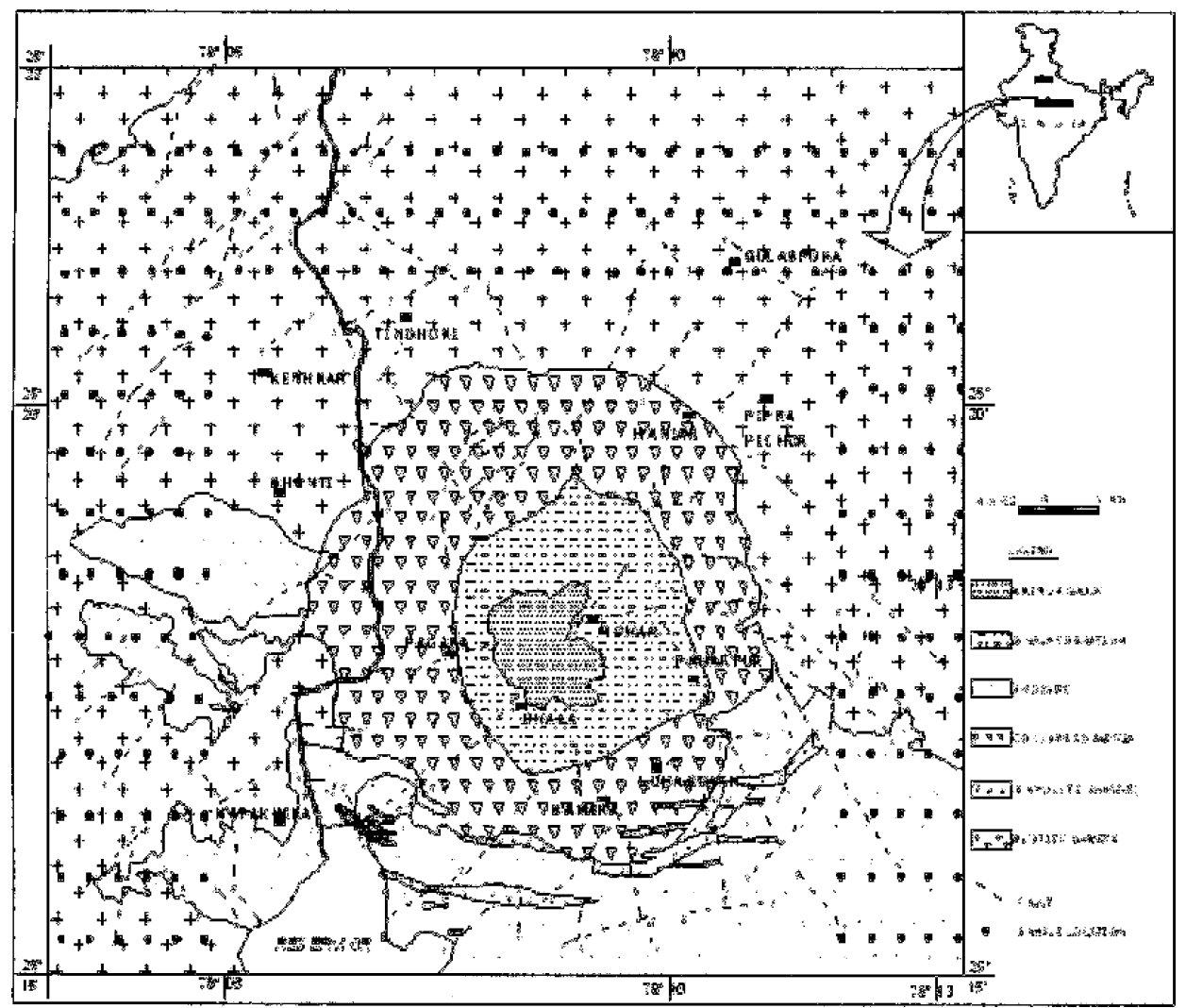

Figure 1. Geological map showing the sample locations around Caldera, Shivpuri District, MP. 
Granite Complex. It is defined by an almost circular outcrop of collapsed ferruginous brecciated granite having $7.5 \mathrm{~km}$ diameter with central diameter of $4.5 \mathrm{~km}$ filled with intracauldron sediments. World wide, the cauldrons are considered favourable geological environment for hosting uranium deposits along with other precious metals and REE minerals. Significant production of these minerals comes from cauldron in countries like Australia, USA and Russia. With world analogy, Atomic Minerals Directorate for Exploration and Research (AMD), India, targeted uranium exploration in the Mohar collapsed cauldron lying within the range of longitude $78^{\circ} 03^{\prime}$ to $78^{\circ} 13^{\prime} 40^{\prime \prime}$ and range of latitude $25^{\circ} 15^{\prime}$ to $25^{\circ} 23^{\prime}$ (Figure 1). The prominent geological formations are shown in Figure 1.

\section{Instrumentation}

Indigenously fabricated portable gamma-ray spectrometer (PGRS) has been used which differentiates between uranium and thorium radioelements through the measurement of gamma activity of ${ }^{214} \mathrm{Bi}(1.76 \mathrm{MeV})$ and ${ }^{208} \mathrm{TI}(2.62 \mathrm{MeV})$. The energies are discriminated by using a $\mathrm{Nal}(\mathrm{Tl})$ crystal of size $1.75^{\prime \prime} \times 2$ " coupled with a PM tube.

The PGRS displays the counts acquired in the four energy windows [Total : $400 \mathrm{KeV}$ 3.0MeV, potassium $\left({ }^{40} \mathrm{~K}\right): 1.36-1.56 \mathrm{MeV}$, uranium $\left({ }^{214} \mathrm{Bi}\right): 1.66-1.86 \mathrm{MeV}$ and thorium $\left({ }^{208} \mathrm{TI}\right): 2.42-2.82 \mathrm{MeV}$ ] along with the concentrations of $\mathrm{eU}_{3} \mathrm{O}_{8}, \mathrm{Ra}_{\text {eq }}$. Th in ppm and $\mathrm{K}$ in $\%$.

Energy calibration of the PGRS is carried out with the help of ${ }^{137} \mathrm{Cs}$ source. The sensitivities of the different channels and stripping ratios needed for inter-channel correction are given in Table 1. The sensitivities are estimated by keeping the PGRS on calibration pads made at Nagpur [5]. The same pad is also used by Purushotham Rao and Venkat Rao [6] for evaluation of performances of various portable gamma ray spectrometers.

Table 1. Sensitivities and stripping ratios for the PGRS and laboratory systems.

\begin{tabular}{|c|c|c|c|c|c|c|c|}
\hline & \multicolumn{3}{|c|}{ Sensitivities } & \multicolumn{4}{|c|}{ Stripping Ratio } \\
\hline & $\mathrm{S}_{\text {Raeq }}$ & $\mathrm{S}_{\mathrm{Th}}$ & $\mathrm{S}_{\mathrm{K}}$ & $\alpha$ & $\beta$ & $y$ & $\mathrm{a}$ \\
\hline $\begin{array}{l}\text { PGRS } 1.75^{\prime \prime} \times 2 " \\
\text { crystal }\end{array}$ & $\begin{array}{c}0.066 \\
\mathrm{cps} / \mathrm{ppm}\end{array}$ & $\begin{array}{c}0.026 \\
\mathrm{cps} / \mathrm{ppm}\end{array}$ & $\begin{array}{c}0.68 \\
\mathrm{cps} / \%\end{array}$ & 0.77 & 0.51 & 0.9 & 0.03 \\
\hline $\begin{array}{l}\text { Lab } 5 " \times 4 " \\
\text { crystal }\end{array}$ & $\begin{array}{c}0.77 \\
\text { cps/ppm }\end{array}$ & $\begin{array}{c}0.59 \\
\mathrm{cps} / \mathrm{ppm}\end{array}$ & $\begin{array}{c}0.019 \\
\mathrm{cps} / \%\end{array}$ & 0.29 & 0.64 & 0.69 & 0.06 \\
\hline
\end{tabular}

Samples are analysed in the lab, using $1 \mathrm{~K}$ MCA coupled with PM tube and $5 " \times 4$ " $\mathrm{Nal}(\mathrm{TI})$ crystal (Figure 2) and the concentrations of $\mathrm{eU}_{3} \mathrm{O}_{8}, \mathrm{U}$ (represented by $\mathrm{Ra}_{\mathrm{eq}}$ ), $\mathrm{K}$ and $\mathrm{ThO}_{2}$ are estimated following the method described in a paper by Acharyulu et al [7]. 


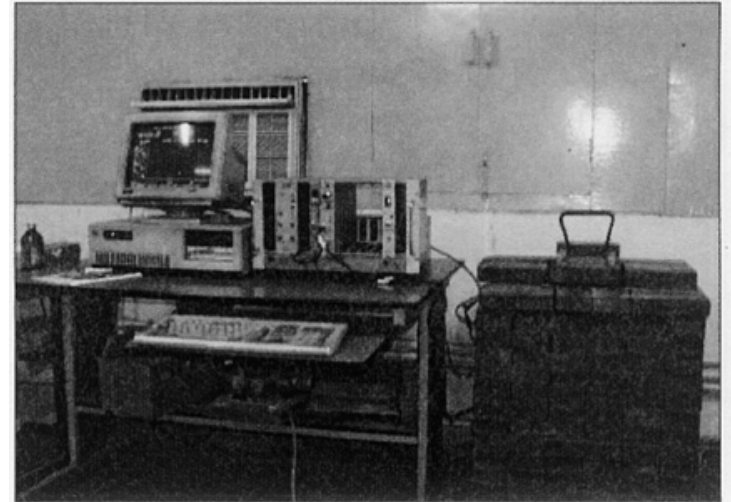

Figure 2. $1 \mathrm{~K} P C$ based $M C A$ system for gamma ray spectrometry of rocks.

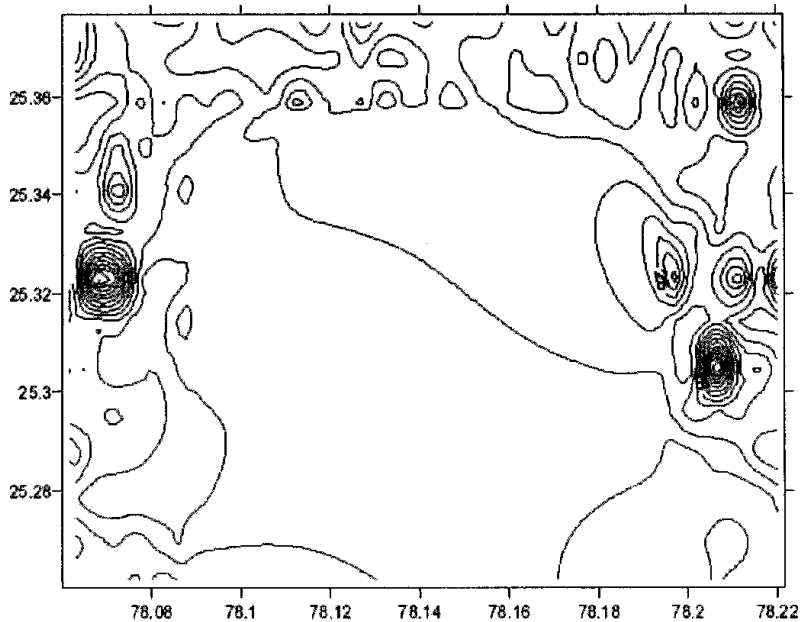

Figure 3a. $\mathrm{Ra}_{\mathrm{eq}}$ (PGRS) contour map.

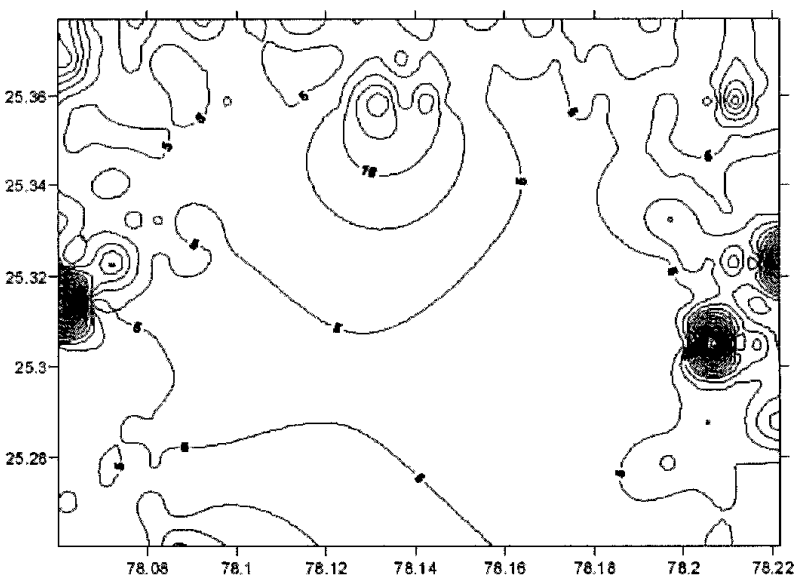

Figure 3b. $\mathrm{Ra}_{\mathrm{eq}}(\mathrm{Lab})$ contour map.

\section{Data collection and presentation}

To systematize the mapping, the area surveyed has been covered on grid pattern $(500 \mathrm{~m} \times 1000 \mathrm{~m})$ and is approximately $118 \mathrm{sq} \mathrm{km} \mathrm{(Figure}$ 1). At each grid point the calibrated PGRS acquires spectrometric data in situ and the radiometric analysis of sample collected from the same grid point are carried out in lab. It gives estimates of $\mathrm{eU}_{3} \mathrm{O}_{8}$ in ppm, $\mathrm{K}$ in $\%, \mathrm{Ra}_{\text {eq }}$ in ppm and $\mathrm{ThO}_{2}$ in ppm. Some of the results are shown in Table 2. For samples from sl. no. 1 to 12 , the PGRS data show an enrichment in favour of $U$ in field represented by $U\left(\mathrm{Ra}_{\text {eq }}\right)>$ $\mathrm{ThO}_{2}$, but lab data show just the reverse of it. For samples from sl. no. 13 to 24 almost both the data show enrichment in favour of Th represented by $\mathrm{ThO}_{2}>U\left(\mathrm{Ra}_{\text {eq }}\right)$.

Over 200 grid points were available for collection of data by PGRS as well as samples drawn for laboratory analysis. The values for $\mathrm{eU}_{3} \mathrm{O}_{8}$ range from 10 to $202 \mathrm{ppm}$ for PGRS and 3 to 190 ppm for the corresponding lab data. Likewise, values for $\mathrm{Ra}_{\mathrm{eq}}$ range from 4 to 91 ppm for PGRS and 2 to $120 \mathrm{ppm}$ for lab data. Values for $\mathrm{ThO}_{2}$ range from 4 to $207 \mathrm{ppm}$ for PGRS and 4 to $320 \mathrm{ppm}$ for lab.

Contour maps (generated using Surfer software) were drawn for $\mathrm{Ra}_{\text {eq }}$ [Figures 3(a) and Figure 3b] and 
Table 2. Selective highlight from the complete set of data to show the reversal of enrichment of uranium.

\begin{tabular}{|c|c|c|c|c|c|c|}
\hline \multirow[b]{2}{*}{ SI. No. } & \multirow[b]{2}{*}{ Long. } & \multirow[b]{2}{*}{ Lat. } & \multicolumn{2}{|c|}{ PGRS } & \multicolumn{2}{|c|}{ Lab } \\
\hline & & & $\begin{array}{l}\mathrm{Ra}_{\mathrm{eq}} \\
(\mathrm{ppm})\end{array}$ & $\begin{array}{l}\mathrm{ThO}_{2} \\
(\mathrm{ppm})\end{array}$ & $\begin{array}{l}\mathrm{Ra}_{\mathrm{eq}} \\
(\mathrm{ppm})\end{array}$ & $\begin{array}{l}\mathrm{ThO}_{2} \\
(\mathrm{ppm})\end{array}$ \\
\hline 1 & 78.0706 & 25.2959 & 11 & 9 & 10 & 31 \\
\hline 2 & 78.08245 & 25.3406 & 12 & 5 & 7 & 12 \\
\hline 3 & 78.07752 & 25.3406 & 10 & 9 & 8 & 25 \\
\hline 4 & 78.06253 & 25.3406 & 16 & 6 & 4 & 30 \\
\hline 5 & 78.0817 & 25.2602 & 21 & 12 & 7 & 41 \\
\hline 6 & 78.07723 & 25.3321 & 13 & 2 & 8 & 26 \\
\hline 7 & 78.07175 & 25.2602 & 15 & 10 & 4 & 43 \\
\hline 8 & 78.11263 & 25.3587 & 24 & 4 & 7 & 33 \\
\hline 9 & 78.13198 & 25.3766 & 16 & 7 & 4 & 30 \\
\hline 10 & 78.08225 & 25.3765 & 11 & 9 & 9 & 17 \\
\hline 11 & 78.127 & 25.3766 & 28 & 11 & 5 & 37 \\
\hline 12 & 78.08708 & 25.3114 & 13 & 3 & 4 & 13 \\
\hline 13 & 78.0773 & 25.3231 & 5 & 11 & 20 & 34 \\
\hline 14 & 78.07218 & 25.3321 & 7 & 7 & 25 & 34 \\
\hline 15 & 78.19667 & 25.3326 & 17 & 16 & 54 & 59 \\
\hline 16 & 78.21672 & 25.3326 & 7 & 11 & 34 & 43 \\
\hline 17 & 78.21663 & 25.3587 & 7 & 9 & 26 & 36 \\
\hline 18 & 78.2117 & 25.3416 & 8 & 7 & 30 & 45 \\
\hline 19 & 78.21665 & 25.3766 & 7 & 9 & 31 & 55 \\
\hline 20 & 78.20175 & 25.6762 & 10 & 9 & 22 & 27 \\
\hline 21 & 78.0625 & 25.3675 & 29 & 34 & 61 & 93 \\
\hline 22 & 78.17683 & 25.3766 & 13 & 15 & 30 & 45 \\
\hline 23 & 78.2217 & 25.3677 & 8 & 7 & 35 & 41 \\
\hline 24 & 78.21643 & 25.3051 & 22 & 25 & 51 & 62 \\
\hline
\end{tabular}

$\mathrm{ThO}_{2}$ [Figures 4(a) and Figure 4(b)] using both the PGRS and lab data which highlight the significant features of the distributions of these elements as follows :

4.1. $U\left(R a_{e d}\right)$ contour map :

The region to the right of longitude $78.18^{\circ}$ shows a fairly good match of densely populated contours whereas the left portion of the map having longitude less than $78.1^{\circ}$ gives a mismatch between the contours of PGRS and corresponding lab data. 


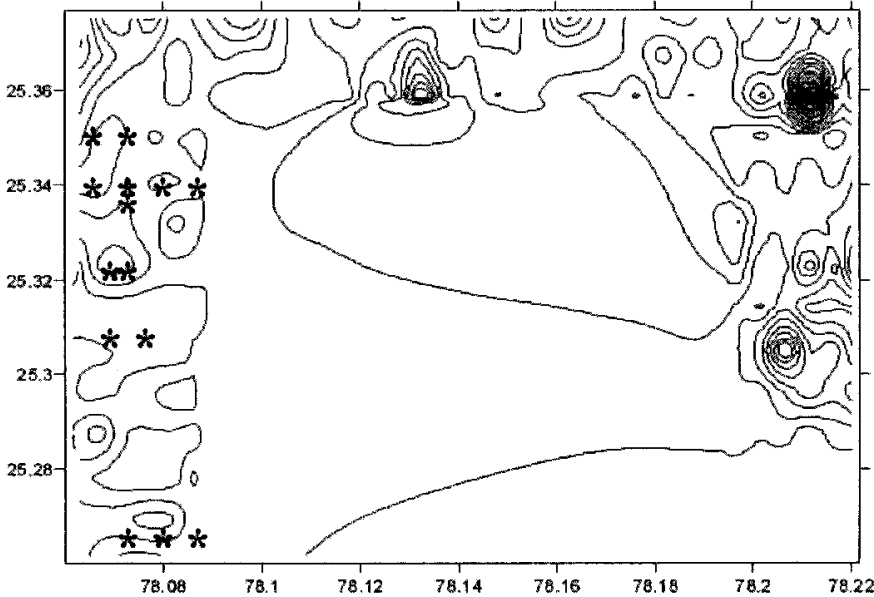

Figure 4a. $\mathrm{ThO}_{2}$ (PGRS) contour map.

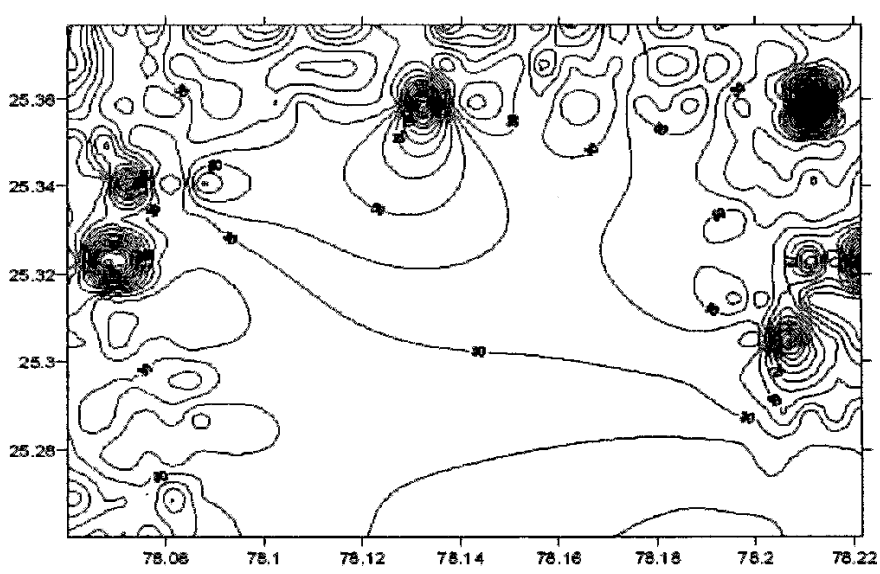

Figure 4b. $\mathrm{ThO}_{2}$ (Labs) contour map.

\section{2. $\mathrm{ThO}_{2}$ contour map :}

Similar observation is found for $\mathrm{ThO}_{2}$ contour maps for PGRS and the corresponding lab data. However densely populated contour, in this case, is observed for the lab data.

\section{Interpretation}

The PGRS data shows uranium enrichment in the region of the map having longitude less than $78.1^{\circ}$ but the lab data does not show such enrichment in this region. For thorium however, the case is just the reverse. The lab data shows enrichment in the region having longitude less than $78.1^{\circ}$ but the PGRS data does not show significant thorium. It is as though the uranium enrichment in the PGRS data of this region is thorium enrichment in the lab data. In rest of the portion the PGRS and lab data match well.

In the context of uncertainties (mentioned in introduction), lack of secular equilibrium and radon migration do not hold good as $\mathrm{U}$ (represented by $\mathrm{Ra}_{\mathrm{eq}}$ ) enrichment in contour map is observed for longitude less than $78.1^{\circ}$. The terrain also has low topographic relief so the mass effect for undulated terrain does not occur.

The concept of volume of the samples seems to play an important part in the interpretation of the above data and contour maps. Sample drawn from each grid point for lab analysis is about $400 \mathrm{gms}$, which is small quantity, compared to the volume seen by the PGRS in the field area. For a plane $(2 \pi)$ geometry $95 \%$ response from the sample is from vertical depth less than $30 \mathrm{~cm}$, while the horizontal response is from a circular area bounded by radius of approximately three times the detection height from the surface [8]. $\mathrm{L} \varphi$ vbrog calculates the volume of the effective sample for a detector whose center is 5 
$\mathrm{cm}$ above the surface as $37 \mathrm{~kg}$ for $1.76 \mathrm{MeV}$ and $49 \mathrm{~kg}$ for $2.62 \mathrm{MeV}$ [9]. So the sample volume in field differs depending upon the energy of the gamma ray being detected. If the distribution of uranium and thorium is homogeneous then $400 \mathrm{gms}$ of sample might be a representative sample but in case of heterogeneity this may not be the situation and mismatch may result between PGRS and lab data. The mismatch is shown by asterix in the contour map of Figure 4(a) lying within longitude $78.06^{\circ}$ to $78.09^{\circ}$ and latitude $25.3^{\circ}$ to $25.36^{\circ}$. This is about $10 \mathrm{sq} \mathrm{km}$ of area.

\section{Conclusion}

PGRS is used in uranium exploration for discriminating between uranium and thorium enriched areas. Here, in this survey of Mohar Cauldron, PGRS was used for the same purpose. Some peculiarities were observed in that the PGRS data obtained between longitude $78.06^{\circ}$ and $78.09^{\circ}$ and latitude $25.3^{\circ}$ and $25.36^{\circ}$ shows uranium enrichment but the data obtained from lab analysis of the samples from the same grid points do not corroborate this. The lab data for this region shows thorium enrichment. So there is a reversal of data in both cases and uranium enrichment of ground data is seen as thorium enrichment of lab data. The area in which reversal occurs is approximately $10 \mathrm{sq} \mathrm{km}$. Reversal occurs because of the imhomogeneity in sample distribution. This study shows that PGRS can be used not only for discriminating between uranium and thorium but also in finding the inhomogeneity of distribution of uranium and thorium in unknown area.

\section{Acknowledgments}

Authors are indebted to Dr. Anjan Chaki, Director Shri P S Parihar, Additional Director; Shri C L Bhairam, Regional Director; Atomic Minerals Directorate, DAE for assigining the programme of work in this terrain. They also thank Shri Naresh Gautam, Draughtsman for his contribution in the preparation of the maps.

\section{References}

[1] L L pvborg, P Kirkegaard and E M Christiansen Design of Nal (TI) scintillation detectors for use in gamma-ray surveys of geological sources, Exploration for uranium deposits IAEA proceedings, Vienna 127 (1976)

[2] C V R Sarma, R Sreehari, K V Ingreji and C S S Murthy Exploration and Research for Atomic Minerals 569 (1992)

[3] M R Wormald and C G Clayton Observation on the accuracy of gamma spectrometry in uranium prospecting, Exploration for uranium deposits IAEA proceedings, Vienna 149 (1976)

[4] S C Jain, V P Gaur, S K Srivastava, K V Nambiar and H P Saxena Geol. Surv. India Spl. Pub. 64 289 (2001)

[5] J G Jadhav, B S Atal, Y Lal and P G Surange Exploration and Research for Atomic Minerals 1 123 (1988) 
[6] V Rao Purushotham and N V Rao, Radiation Protection and Environment 22182 (1999)

[7] A A P S R Acharyulu, B S Murty and B K Bhaumik, Proc. Indian Acad. Science, Earth Plan. Sci. 113321 (2004)

[8] S G Tiwari and S S Raghuwanshi Some problems on the range of investigation in airborne gamma-ray spectrometry, Uranium 14 (Netherlands) 67 (1987)

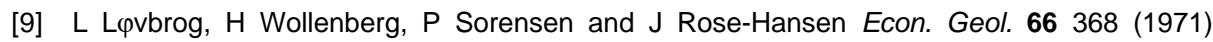

